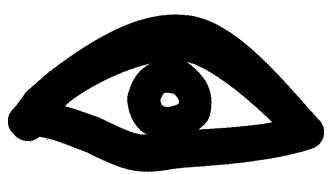

\title{
A Formação de Professores na Licenciatura em Educação do Campo
}

\section{The training of teachers in Education degree in the field}

\author{
Rosemeri Scalabrin*, Marcos Paulo Alves Cruz** \\ *IFPA/Brasil, ** Centro Educacional Leonardo da Vinci
}

\begin{abstract}
Resumo
Este estudo aborda a formação de professores na Licenciatura em Educação do Campo desenvolvida pelo Campus Rural de Marabá, por meio do Plano de Formação de Profesores da Educação Básica- Plataforma Paulo Freire, com objetivo de identificar a contribuição da qualificação por áreas de conhecimento para a superação da fragmentação do conhecimento. $\mathrm{O}$ estudo constatou que o curso materializou a construção do currículo por área no Ensino Superior e efetivou a relação dialógica entre os professores da instituição, Associação das Casas Familiares Rurais e Comissão Pastoral da Terra na coogestão e acompanhamento das ações nos tempos-comunidade.

Palabras clave: formação de profesores, educação do campo, licenciatura em educação do campo.
\end{abstract}

\section{Abstract}

This study discusses the training of teachers in Education degree in the field developed by the Rural Campus of Maraba, through the training plan for Teachers of basic education-Paulo Freire Platform, in order to identify the contribution of qualification for knowledge areas to overcome the fragmentation of knowledge. The study found that the course curriculum by building materialized area in higher education and realized the dialogical relationship between teachers of the institution, Association of Rural family homes and Land Pastoral Commission on coogestão and monitoring of actions in the times-community.

Keywords: training of teachers, field education, degree in the education field.

\section{Contexto histórico de criação da LPEC do CRMB/IFPA/ PARFOR}

O modelo de educação no Brasil é organizado em séries e disciplinas que fragmentam o conhecimento pelo fato do mesmo ter sido pensado para a sociedade urbana, pois acreditava-se na extinção do campo, o que não se consolidou, pois segundo o Censo de 2010 um sexto da população continua a residir no meio rural.

Isto levou a escassez de escolas no meio rural e a precariedade das instalações físicas das escolas existentes, bem como a inexistencia de investimento na qualificação de professores e na organização curricular adequada ao modo de vida e produção do campo, ocasionando a repetência e a evasão, devido a ausencia de diálogo com os saberes locais, a descontextualização das práticas docentes, gestões desprovidas de conhecimentos capaz de redirecionar o ensino, fortalecendo, com isto, o êxodo rural.

No contexto de questionamento ao modelo urbano de educação, os movimentos sociais e sindicais do campo, a partir dos anos de 1990, tomando como referencia as escolas em alternância na França e na Itália, passaram a desenvolver experiências educativas fora da escola, através da Associação das Casas Familaires Rurais com currículo e metodologia adequado a realidade do campo, conforme assegura a Lei de Diretrizes e Bases da Educação Nacional, 9394/96, em seus artigos $23^{\circ}$ e $28^{\circ}$.

Somando isso, dados do diagnóstico do MEC(2004) demonstraram a brutal disparidade existente entre as populações urbana e rural em termos de escolaridade e as limitações temporais para construir a eqüidade educacional, cujo problema é crônico, pois "mesmo que houvessem medidas enérgicas e investimento financeiro, a população rural do Brasil levaria mais de 30 anos para atingir o atual nível de escolaridade da população urbana do país" (BRASIL/MEC, 2004), o que exigiria do governo brasileiro investimento na politica de formação de profesores, com vistas e redimir esta dívida histórica.

Foi nesse contexto que emergiu o Movimento Nacional Por uma Educação do Campo, o qual aglutinou Universidades, Comissão Nacional do Bispos do Brasil e os Movimentos Sociais do Campo, na luta pela ampliação do acesso a educação do e no campo com de qualidade.

Este movimento conseguiu colocar o debate sobre a educação do campo na agenda dos governos federal e estaduais; forçou a criação do Programa Nacional de Educação na Reforma Agrária (PRONERA), para desenvolver cursos voltados para as populações do campo, inicialmente no âmbito da Educação Básica, ampliando-se posteriormente, para o ensino superior e a pós-graduação; be como, a criação da Comissão de Educação do Campo inter-mineterial, coordenada pelo MEC, e da Secretaria de Educação do Campo (SECADI) para discutir sobre a política de educação do campo.

Atendendo a demanda pela formação de professores que atuam nas escolas do campo, o governo federal criou os programas de formação inicial, como: o Programa Nacional de Formação de Professores do Campo (PROCAMPO) e o Plano de Formação de Profesores da Educação Básica-Plataforma Paulo Freire (PARFOR) e programas de formação continuada, como: PROJOVEM CAMPO SABERES DA TERRA e o Programa Nacional de Educação do Campo (PRONACAMPO), o qual também financiava a construção de escolas e material didático especifico para as escolas do campo.

Foi neste contexto que o curso de Licenciatura Plena em Educação do Campo (LPEC) foi criado no Institutito Federal de Educação, Ciência e Tecnología do Pará (IFPA), com vistas a qualificar os profesores por área de 
conhecimento para questionar e superar a fragnemtação disciplinar, a descontextuaização do currículo e das práticas docentes.

Neste sentido, a referida licenciatura visou formar os professores em áreas de conhecimento a saber: Ciencias Humanas e Socias; Ciências da Natureza e Matemática; Linguagens, Arte e Literatura; e, Ciências Agrárias, com vistas a garantir um currículo que atendesse as necessidadese e desejos das populações do campo, garantindo a permanência das escolas no espaço físico do campo e com um currículo que atenda as especificidades de trabalho, produção e vida no campo, de modo que os docentes em sua atuação respeitem os saberes que os sujeitos trazem ao chegar a ela, de modo que a escola contribua na construção de um projeto de campo e de sociedade.

Este contexto de luta pelo acesso a educação, levou os movimentos sociais e sindicais do campo da região Sudeste do estado do Pará, a reivindicar a criação de escolas técnicas e, neste contexto, conquistaram a criação do Campus Rural de Marabá/IFPA, como um campus votado para atender únicamente as populações do campo e as suas demandas de formação.

Nesta perspectiva, no ano de 2011, este Campus, atendeu a demanda da Associação das Casas Familiares Rurais (ARCAFAR/PA) e da Comissão Pastoral da Terra de Tucuruí (CPT) pela qualificação de profesores das Casas Familiares Rurais do Estado do Pará por meio da oferta da Licenciatura em Educação do Campo, encaminhou junto a Pró-Reitoria de Ensino do Instituto Federal de Educação, Ciência e Tecnologia do Pará (IFPA), o pedido de criação do curso de referida Licenciatura, via Plataforma Paulo Freire (PARFOR), a o qual foi aprobado.

O curso de Licenciatura em Educação do Campo do IFPA foi desenvolvido no período de 2011-2015, e atendeu seis turmas, desenvolvidas nos campi do IFPA localizadas em Marabá, Altamira, Santarém, Breves, Bragança, Abaetetuba e Belém, envolvendo educadores cerca de mais de 30 municípios do Estado do Pará, formando cerca de 240 professores, sendo $40 \%$ na área de Ciências na Naureza e Matemárica e $60 \%$ na área de Ciencias Humana e Sociais.(CRMB, 2015).

$\mathrm{O}$ referido curso teve como objetivo formar o licenciado em Educação do Campo para atuar nas séries finais do Ensino Fundamental, no Ensino Médio, na Educação de Jovens e Adulto em duas áreas conhecimento a saber: Ciências Sociais e Humanidades (nos componenstes curriculares de História, Geografia e Sociologia, Filosofia); Ciências da Natureza e Matemática (nos componentes de Ciências, Química, Física, Matemática e Biologia), bem como na gestão de espaços comunitarios.

Nesta perspectiva, o Projeto Político-Pedagógico do Curso contempla a formação mutiltidisciplinar nas duas áreas acima citadas, com carga horária total de 4.760 horas por cada área de concentração e que confere o diploma de Licenciado em Licenciatura em Educação do Campo aos estudantes.

A matriz do curso contém o eixo articulador e de oito eixos, conforme destacamos a seguir, e cada eixo comtém oito componentes curriculares, desenvolvidos em atividades na escola e na comunidade:

Eixo articulador: Educação e Formação de Educadores/as do Campo na Amazônia Paraense

Eixo 1: História de Vida e Construção de Saberes;

Eixo 2: Espaço Agrário e o sócio-ambiental como matriz da luta pelo desenvolvimento sustentável do campo;

Eixo 3: Sistema de Produção e Processos de Trabalho no Campo;

Eixo 4: Estado. Movimentos Sociais e Políticas no Campo;

Eixo 5: Educação do Campo, Currículo e Práticas Sociais:

Eixo 6: Juventude do Campo e Transformações Sócio-ambientais;

Eixo 7: Sujeitos Sociais e Diversidade na Prática Educativa Do Campo;

Eixo 8: Prática Docente e Educação do Campo.(CRMB/ IFPA, 2011)

A estratégia de integração dos eixos entre si e com os componentes curriculares, se dá pela relação entre os tempos-escola e comunidade, visto que as pesquisas realizadas pelos estudantes, a cada tempo comunidade, são sistematizadas e socializadas, com vistas a subsidiar o planejamento docente.

A alternância de tempos e espaços no curso, pretendeu demonstrar, na prática, a possibilidade do desenvolvimento de uma educação de qualidade a partir da ampliação da forma tradicional e tecnicista, cuja ações devem estar para além da sala de aula, romper com a idéia da aula como unidade única do trabalho pedagógico, redimensionar a lógica do estudo e do trabalho docente, alterar a lógica de constituição do plano de aula, superar a cultura individual e isolado do trabalho docente e o ensino de transmissão de informações para contribuir na transformação da realidade, construir um currículo que tenha como centralidade o estudo dos fenômenos da realidade (da vida) sem perder os referencias das ciências básicas, bem como do conjunto de conhecimentos historicamente sistematizados e sem desconsiderar que certos conteúdos implicam em pré-requisitos e em métodos específicos para sua apropriação e reconfiguração do papel do educador (CRMB, 2011).

De acordo com o projeto do curso, os elementos constitutivos da formação dos licenciados foram:

i)Projeto Político-Pedagógico da escola: é o documento que contém os objetivos, a missão, a visão, as diretrizes e as ações da escola ao longo de 3 anos, por isso expressa a síntese das exigências sociais e legais do sistema de ensino e deve expressar os propósitos e as expectativas da comunidade escolar. Ele deve expressar da cultura da escola com sua recriação e desenvolvimento para o que se faz fundamental que sua construção seja coletiva. O PPP é "a sistematização, nunca definitiva, de um processo de Planejamento Participativo, que se aperfeiçoa e se concretiza na caminhada, que define claramente o tipo de ação educativa que se quer realizar", assim oportuniza "a construção da identidade da instituição" por meio da "organização e integração de atividades práticas" e 
reflexivas da instituição escolar (VASCOLNCELOS, 2002, p. 169).

ii) Calendário Escolar: requer outras formas de organização, a luz dos processos produtivos locais, conforme garante a LDB, 9394/96, em seus artigos $23^{\circ} \mathrm{e}$ $28^{\circ}$.

iii) Formação Integral e Integrada: prima pelo desenvolvimento humano daí porque as práticas curriculares visam contemplar uma compreensão global do conhecimento, com vistas a promoção da interdisciplinaridade e da integração de conhecimentos, possibilitan compreender a realidade para além de sua aparência fenomênica, pois os conteúdos de ensino não têm fins em si mesmos, nem se limitam a insumos para o desenvolvimento de competências; antes os conteúdos de ensino são conceitos e teorias que constituem sínteses da apropriação histórica da realidade material e social pelo homem (Ramos, 2005).

iv) Conceito de Educação Rural versus Concepção de Educação do Campo: A concepção de Educação do Campo se referencia nos termos: "do e no campo, em que no campo, indica a necessidade da escola estar localizada no espaço geográfico, político e social do campo, possibilitando a apropriação e sistematização do conhecimento produzido no âmbito da ciência; e, do campo, representa a educação construída/produzida com as populações do campo, a partir de seus interesses e necessidades, implicando na estruturação de um currículo que priorize e valorize os valores expressos por essas populações" e seu protagonismo. (Scalabrin, 2011, p.18). Esta concepção se ancora na tríade Campo-Educação-Políticas Públicas discutida por Molina (2003), bem como na tríade, como a tríade Produção-Cidadania-Pesquisa, discutida por Michelotti (2007), porém o destaque de ambas está na elaboração de políticas públicas e a relação entre as diferentes áreas de conhecimento (a educação, a sociologia, a economia, a agronomia, a política, a história, a filosofia) e configura o rural como um lócus transdisciplinar de produção e sistematização de conhecimento, ancorado na heterogeneidade, dinamismo e diversidade, cujo projeto de desenvolvimento é centralidade na produção camponesa (SCALABRIN, 2011).

v) Relação Escola-Sociedade: Esta relação se fundamenta nas tríades, visto é papel da escola contribuir na construção do projeto de campo.

vi) Currículo interdisciplinar via tema gerador: Visando quebrar a lógica da fragmentação disciplinar, o currículo interdisciplinar via tema gerador, deve garantir a vóz dos sujeitos no currículo, pois os conhecimentos a serem trabalhados são selecionados a partir de situações-limite social na visão dos sujeitos, as quais expressam uma situação de opressão não percebida pelos mesmos, um limite explicativo para os problemas vivenciados. Estes ao serem problematizados e refletidos oportunizam visão critica da realidade. Nesta proposta, os componentes dos cursos têm caráter de previsão, subordinando-se às necessidades concretas dos educandos, detectadas pelo docente no desenvolvimento do processo educativo, não se desenvolvendo isoladamente ou em bloco, mas de forma transdisciplinar, constituindo um movimento em espiral no qual, a cada atividade os conhecimentos adquiridos e construídos anteriormente podem ser trabalhados com uma complexidade maior, sendo abordados a partir de uma perspectiva regional sem, contudo, desconsiderar os aspectos nacionais e as características locais.

viii) A estrutura curricular da LPEC e a organização de Tempos e Espaços formativos como propiciadores do processo de construção do conhecimento composta pela apropriação dos tempos e espaços formativos de modo diferenciado com vistas a instigar a possibilidades a intervenção seja em torno do "[...] momento em que conhecemos o conhecimento existente produzido que representa, preponderantemente, o da docência, o de ensinar e aprender conteúdos" como o momento em que "produzimos o novo conhecimento, que é preponderantemente, o momento da pesquisa" (Freire, 1992, p. 192).

Os tempos e espaços formativos são compreendidos como momentos intrínsecos, posto que "não há docência verdadeira em cujo processo não se encontre a pesquisa como pergunta, como indagação, curiosidade, criatividade, assim como não há pesquisa, cujo andamento necessariamente não se aprenda porque se conhece e não se ensina porque se aprende" (Freire, 1992, p. 192) essa diversidade de atividades integradas revela formas e tempos próprios de organização e produção de conhecimentos que foram dando sentido e significado ao processo formativo e a vida dos sujeitos envolvidos.

Segundo Molina (2003, p. 124) “esta é uma das marcas centrais deste paradigma da Educação do Campo: o esforço de associar a educação à organização da produção agrícola, aos valores que se quer instituir nas relações de trabalho no campo".

\section{Métodos}

Esta estudo foi realizado, por meio da análise do percurso formativo vivenciado nos anos de 2011 a 2105 , a partir de reflexões realizadas em conjuto com a coordenação do curso e na atuação como professora dos componetes curriculares: História de Vida; Metodologia Científica; Práticas Educativas e Estágio Supervisionado voltado para o Ensino Fundamental, Ensino Médo, Educação de Jovens e Adultos e Gestão de espaços comunitários na turma do Campus Rural de Marabá, do referido curso, bem como na realização das ações dos tempos-comunidade no decorrrer do curso.

Além disso, se refeenciou no estudo e análise de documentos do curso, tais como: Projeto Político-Pedagógico; Planos de Orientação das pesquisas; Planos de estágio; Relatórios dos Seminários de Educação do Campo reaizados em nove municipios; Relatórios de pesquisa dos tempos-comunidade produzidos pelos educandos do curso de LPEC/PARFOR/CRMB, Estado do Pará, Planos de Aula e Avaliação do curso.

\section{Resultados e Discussão}

A integração curricula, no curso de Licenciatura em Educação do Campo, ocorreu pelos eixos e através da 
pesquisa realizada pelos estudantes nos tempos comunidade.

No eixo 1 a centralidade esteve na história de vida e da localidade com o levantamento da realidade sócio-educacional local.

No eixo 2, as atividades de pesquisa estabeleceram a intersecção entre os eixos 1 e 2 , de modo a tomar a realidade como objeto de conhecimento, e com a finalidade de identificar práticas, eventos, marcos, acontecimentos vivido pelos camponeses no contexto sócio-histórico regional - aspectos que fazem parte da história, da cultura e das práticas educativas desse grupo social na região.

$\mathrm{O}$ eixo $3^{\circ}$ esteve centrado na pesuisa em um lote com produção diversificada e outro com produção homogénea com vistas a levantar as vantagens e desvantagens de tais processos produtivos e refeltir junto a comuniade. Esta pesquisa dialogou com a pesquisa do $2^{\circ}$ tempo-comunidade e esteve articulada ao $4^{\circ}$ tempo-escola, a partir das atividades integradoras, tais como: $1^{\mathrm{o}}$ momento: partilha de saberes com a comunidade; $2^{\circ}$ momento: construção individual de um paper; $3^{\circ}$ momento: a pesquisa; $4^{\circ}$ momento: a coleta de materiais utilizados tempo comunidade seguinte.

$\mathrm{O} 4^{\circ}$ Tempo-comunidade foi o estimulador da reflexão da ação na formação de Educadores do Campo e é inter-relacionado ao eixo 4, o qual trouxe elementos para o eixo do $5^{\circ}$ tempo-escola. Neste tempo, os estudantes também organizaram os seminários de Educação do Campo nos municípios envolvendo movimentos sociais e poder público local.

As pesquisas realizadas em cada tempo-comunidade despertou para a importancia de melhor conhecer a realidade, bem como a necessidade de assumirem-se como profesor perquisador, algo até então imperceptível na ação docente dos mesmos.

A partir do $5^{\circ}$ Eixo, o foco das atividades dos tempos-comunidade estiveram voltadas para os estágios I, II, III e IV, em nível de Ensino Fundamental, Ensino Médio, Educação de Jovens e Adultos e Gestão de espaços comunitarios.

$\mathrm{Na}$ realização dos quatro tempos-comunidade de estágio, vivenciou-se dificuldades, em espcial no primero deles, devido a resistencia dos estudantes em planejar a ação docente em cada tempo.

Isto ocorreu devido as escolas do campo não possuirem a prática de planejamento coletivo e a produção do plano de aula individual articulado pro área. Assim, o plano existente não se materializava na pratica, segui apenas um protoco.

Porém, ao vivenciar o estágio observação, os estudantes começaram a perceber os problemas existente no proceso de ensino-aprendizagem pela ausência de planejamneto docente. E, ao analizar o planos de aula dos profesores da escola em que estagiavam a luiz das ações docentes desenvolvidas, passaram a perceber a incoerência ente o proposto e o desenvuelto. Outro desafio estava em não avaliar o colega, mas refletir sobre as próprias práticas.

Nos momentos do estágio-vivência, a dificuldade esteve em convencer a direção da escola e os colegas profesores sobre a necessidade de discutir acerca da importancia do planejamento coeltivo da ação docente, visto que os estudantes atuaram em sala de aula junto com o docente da turma. Assim, ao desenvolver a docencia na turma de outros profesores foram desafiados a envolve-los no planejamento.

Este prcesso gerou uma nova dinámica na maioria da escolas do ampo que os estudantes atuaram, visto que ao realizar o planejamento das aulas, as mesmas passaram a ser mais dinámicas, viabilizando o diálogo entre o saber dos alunos e os conhecimentos escolar, cujos temas de estudo estiveram vincrlados a realidade local, de modo que após a atividade de estágio os alunos passaram a cobrar uma educação de qualidade dos professores e gestore.

Somado a isto, o curso de Licenciatura em Eduação do Campo representou a possibilidade de acesso a educação superior pelos profesores do campo, os quais não possuiam condições financeiras para se deslocar de seus municipios e estudar na capital, cujas distancias variam entre quinhentos e mil quilomentros. Assim ele representa em primeira análise a inclusao educacional.

Representou, também, a materialização de uma matriz de educação do campo no ámbito do Ensino Superior, capaz de qualificar os profesores para promover a recriação da escola do campo, pela ressignicação da escola na sua relação com a sociedade, pela organização de um currículo e de um calendário escolar adequado ao processo produtivo do campo, bem como pela gestão coletiva da escola e do ensino.

Representou, ainda, o rompimento com o modelo urbano de educação como único no Brasil, pela aprovação e reconhecimento do referido a Licenciatura pelo Ministério da Educação, organizada em áreas de conhecimento e fundamentado no respeito as diversidades e modos de vida existentes no campo.

Nesta perspectiva, a referida licenciatura oportunizou a qualificicação dos profesores para a construção coletiva do Projeto Político-Pedagógico das escolas do campo, do currículo, do calendário escolar, do planejamento coletivo, da avaliação, bem como o debate sobre o papel da escola do campo a partir da concepção da educação $d o$ e no campo, construindo um novo sentido para a educação nas escolas do campo, marcada pela formação escolar para restabelecer a ligação com a vida.

Deste modo, a preocupação com a formação na licencuatura esteve em não restringi-la únicamente ao campo das metodologías, entendida como aulas dinâmicas ou alternâncias de ações para a melhoria da transmissão do conhecimento; mas principalmente com a política educacional capaz de provocar e promover a organização curricular nas escolas do campo, pautada no debate sobre o que ensinar? para que ensinar? e quem ensinar? (Freire, 1975); e, no diálogo de conhecimento e a problematizção de realidade como fundamentais no processo de construção do conhecimento.

Neste sentido, o estudo sobre as práticas curriculares dos profesores percorreu, de um lado, pela busca de superação da concepção instrumental de conhecimento baseada lógica dos conteúdos assumido como objeto de conhecimento, os quais são utilizados para a adaptação ao contexto social, e pautado na crença de que somente da ação individual do professor, as dinâmicidade e a 
ludicidade são capazes de, por si só, alcancar a aprendizagem dos educandos, e de outro lado, pela afirmação de concepção ético-crítia do conhecimento, fundamentado na compreensão de que educadores e educandos são sujeitos, a realidade concreta é objeto de cohecimento, cujo conhecimento cientifíco deve ser acessado para promover a trasnformação do contexto sócio-histórico (Gouvea, 2013).

$\mathrm{O}$ acumulo dos debates e das pesquisas realizadas nos tempos-comunidade no decorrer do curso, demonstram que é preciso avançar na reformulação da política educacional municiapal, estadual e federal, no sentido de colocar em prática os avanços da legislação educacional como a LDB 9394/96 e as diretirzes da educação do campo (Resoluções 001/2002 e 001/2008), , bem como avançar na materialização da gestão coletiva do ensino seja pelas Secretarias estaduais e municipais de educação, seja nas escolas do campo.

Para isto, a afrmação desenvolvida tratou como fundamental o conhecimento não apenas sobre as teorías de currículo, mas também vivenciou o proceso de construção do currículo interdiciplinar via tema gerador, partido da realidade na visão dos sujeitos, vivenciando os três passos de sua construção: estudo da realidade (ER), organização do cohecimento (OC) e aplicação do conheciento (AC). (Pernambuco e Paiva, 2006).

Neste sentido, identificamos que o principal desafio dos profesores esteve na aplição do conhecimento, na medida em que a maioria delas, mesmo atuando em escolas do campo, abandonavam a programação de ensino construida coletivamente a partir da realização da pesquisa sócio-antropológia e da organização do conhecimtento (seleção das falas, escola do tema gerador, elaboração do contra-tema, da programação de ensino e do plano de aula), para desenvolver os conteúdos descontextualizados do livro didático ou da lista de conteúdos enviadas pelas Secretarias municipais de ensino.

Isto demonstra a dificuldade em desconstruir pré-conceitos enrraizados na cultura educativa, para asumir, de falto, nova postura diante do proceso de construção do conhecimento.

Discutindo sobre o que significa partir da realidade Freire (1981) destaca que representa mais do que reconhecer nela os dados e fatos existentes, é acima de tudo entender qual a percepção deles que os sujeitos da comunidade ou bairro estão tendo. Entretanto, esta é uma tarefa de difícil realização, dada a dificuldades em ouvir e de entender os sujeitos locais.

Esta dificuldade, segundo Valla (2000), não advém da questão lingüística, mas sim da postura assumida pelos professores diante do conhecmento, bem como pela ausência de conhecimento sobre o que os grupos populares estão falando, dada a sua diversidade e as suas raízes culturais, local de moradia, e a relação que mantêm com os grupos que acumulam capital.

É por isto que para desenvolver a educação libertadora, não basta mudar as metodologias. É preciso discutir quais conhecimentos interessa a classe trabalhadora, neste caso os camponeses, indígenas, quilombolas, extrativistas, caiçaras, entre outros.

\section{Referências}

Brasil. Ministério da Educação. DB 9394/96.

Brasil/Mec.(2004). Relatório situacional das escolas do campo no Brasil. Setembro.

Crmb/Ifpa.(2011). Projeto Político-Pedagógico do Curso de Licenciatura em Educação do Campo. Jul Crmb/Ifpa.(2013). Relatório de Avaliação do Curso de Licenciatura em Educação do Campo. Julho.

Ccmb/Ifba.(2014). Orientações para os Tempos Comunidade. Dezembro.

Freire, Paulo. (1975). Pedagogia do Oprimido. $3^{\text {a }}$ ed. Rio de Janeiro: Paz e Terra.

Freire, P.(1981). Criando métodos de pesquisa alternativa: aprendendo a fazê-la .melhor através da ação. In: Brandão, C. R. Pesquisa Participante. São Paulo, brasiliense

Freira, P.(1992). A importância do ato de ler em três artigos que se completam. São Paulo, Cortez Editora.

Gouveia da Silva, F. A. (2013). O Currículo na Práxis da Educação Popular: projeto pedagógico interdisciplinar - Tema gerador via rede temática. In: Práticas Coletivas na Escola. Pernambco e Paiva (Org.). São Paulo: Mercado de Letras.

Libânio, J. C (1994). Didática. Coleção Magistério. São Paulo: Cortez.

Molina, M.C.(2003) A Contribuição do PRONERA na Construção de Políticas Públicas de Educação do Campo e Desenvolvimento Sustentável. Programa de Pór-Graduação da Universidade de São Paulo (Tese de doutorado). São Paulo. Brasil.

Pernambuco, Marta Maria de Almeida Castanho \& PAIVA, Irene. Metodologia e Conteúdo. Caderno Educação e Realidade $\mathrm{n}^{\circ}$ 15. UNIDIS/UFRN, 2006.

Ramos, M. N. (20015). Possibilidades e Desafios na Organização do Currículo Integrado: In: RAMOS, M. N., Frigotto, G. Ciavatta, M.(org) Ensino Médio Integrado: Concepção e Contradições. São Paulo: Cortez. p. 106-127.

Scalabrin, R. (2011). Diálogos e Aprendizados na formação em Agronomia para assentados.Tese (doutorado) - Pós-Graduação em Educação, Universidade Federal do Rio Grande do Norte, Brasil.

Vasconcellos, C.S.(2002). Planejamento: projeto de ensino-aprendizagem e político-pedagógico. São Paulo: Libertad..

Valla, V. V(2000). Procurando compreender a fala das Classes Populares.N: Valla, v. v. Saúde e Educação. Rio de Janeiro, DP\&A. 